\title{
The Response Analysis of BR Related Genes at Low Temperature in Potato Sprout Regulation
}

\author{
Di Xueni ${ }^{1}$, Deng Mengsheng ${ }^{1}$, Zou Xue ${ }^{1,2}$, Li Yanan ${ }^{1,3}$, Ni Su ${ }^{1,3}$, Wang Xiyao ${ }^{1,3 \unrhd}$ \\ 1 College of Agronomy, Sichuan Agricultural University, Chengdu, 611130, China \\ 2 Mianyang Academy of Agricultural Sciences, Mianyang, 621023, China \\ 3 National Demonstration Center for Experimental Crop Science Education, Sichuan Agricultural University, Chengdu, 611130, China \\ \ Corresponding author Email: wxyrtl@163.com \\ Molecular Plant Breeding, 2019, Vol.10, No.16 doi: $\underline{10.5376 / \mathrm{mpb} .2019 .10 .0016}$ \\ Received: 26 Aug., 2019
}

Accepted: 15 Oct., 2019

Published: 28 Oct., 2019

Copyright (c) 2019 Di et al., This article was first published in Molecular Plant Breeding (2018, 16(13): 4143-4150) in Chinese, and here was authorized to translate and publish the paper in English under the terms of Creative Commons Attribution License, which permits unrestricted use, distribution, and reproduction in any medium, provided the original work is properly cited.

Preferred citation for this article:

Di X.D., Deng M.S., Zou X., Li Y.N., Ni S., and Wang X.Y, 2019, The response analysis of BR related genes at low temperature in potato sprout regulation, 10(16): 121-127 (doi: $\underline{10.5376 / \mathrm{mpb} .2019 .10 .0016)}$

\begin{abstract}
Brassinosteroids (BR) plays an important role in regulating plant growth. We found that the expression of BR synthesis and signal transduction genes were up-regulation when potato dormancy was released, and suckering agents can inhibit the expression of Methylsterol monooxygenase 1 (SMO1), Delta24-sterol reductase 1 (DWF1), Protein BR insensitive 1 (BRI), BR-signaling kinase (BSK) and Cyclin D3 (CYCD3) genes in potato tuber. Besides, we found that the storage period among different cultivars are significant different at low temperature. Low temperature can obviously extend cultivar 'Favorita' storage time than cultivar 'Mira'. In order to explore the response of BR genes to potato sprout at low temperature. This study will analyze the expression of BR synthesis, signal transduction and regulation genes at from cultivar 'Favorita' and cultivar 'Mira' which both cultivars are storage at low temperature $\left(4^{\circ} \mathrm{C}\right)$ and room temperature $(23 \pm 2)^{\circ} \mathrm{C}$ environment by qRT-PCR technique. The results showed that the expression of DWF1 and BRI1 are decreased in both cultivars by low temperature treatment. The expression of SMO1, BSK and CYCD3 genes are decreased in cultivar 'Favorita'by low temperature treatment. While, the expression of SMO1, $B S K$ and $C Y C D 3$ genes in'Mira'are increase by temperature treatment. It shows that low temperature influences the expression of SMO1, BSK and CYCD3 genes in cultivar 'Favorita', which results in the long dormancy period of the cultivar 'Favorita'. These results will provide the theoretical basis in elucidating the BR mechanism of potato sprout, breeding variety selection and new technology research and development of potato storage regulation.
\end{abstract}

Keywords Potato; Dormancy; Sprout; Low temperature; Brassinosteroids

\section{Background}

As the fourth largest grain crop in China, potato is a both grain and vegetable crop, which is rich in amino acids, vitamins, mineral elements, etc. (Tian et al., 2017). Potato storage plays an important role in potato industry. However, about 4.1 million tons of potatoes are lost each year in China because of improper storage (Zhang et al., 2012). The dormancy period of potato is affected by temperature, humidity, and growth regulator. $85 \%$ of the humidity was considered to be the optimum humidity for prolonging the storage time of the potato, and the 4 $\mathrm{mg} / \mathrm{L}$ abscisic acid treatment could also significantly prolong the storage time of the potato (Zhong et al., 2017). At present, low temperature is often used as the main method to prolong the storage time of potato (Si et al., 2007, Chinese Potato Journal, (2): 104-107). The dormancy period of potato is not only affected by external conditions, but also closely related to its own genotype (Bamberg, 2010; Fan et al., 2009). We found that brassinosteroids (BR) plays a key role in dormancy release and germination of potato.

As polyhydroxyl steroid plant hormones, brassinosteroids is involved in the regulation of plant growth and development, including promoting seed germination, inducing flowering, plant photomorphogenesis and improving plant stress resistance (Clouse and Sasse, 1998; Steber and McCourt, 2001). Zou et al. (2017) analyzed the expression of BR synthesis and signal transduction in potatoes of different dormancy, which are storage at suckering agents and room temperature, and found that the genes expression of BR synthesis Delta24-sterol 
reductase 1 (DWF1), Methylsterol monooxygenase 1 (SMO1), Protein BR insensitive 1 (BRI1), BR-signaling kinase (BSK) and Cyclin D3 (CYCD3) were up-regulation when potato dormancy was released. BRs play an important role in the release of dormancy and germination of tubers. Besides, we found that the suckering agents can inhibit the expression of above genes in potato tuber.

In order to explore the response of BR genes SMO1、BRI1 DWF1 BSK and CYCD3 to potato sprout at low temperature, this study analyzed the expression of BR synthesis, signal transduction and regulation genes at from cultivar 'Favorita' and cultivar 'Mira' which both cultivars are storage at room temperature $(23 \pm 2)^{\circ} \mathrm{C}$ and low temperature $\left(4^{\circ} \mathrm{C}\right)$ environment. We observed the growth of apical sprout by stereoscopic microscope, and measured its length. qRT-PCR technique was used to analyze the expression of the gene under different dormancy and germination stages.

\section{Results and Analysis}

\subsection{Sprout length measurement of 'Favorita' and 'Mira'}

Observed the microscopy of potato apical sprout in 'Favorita' at room temperature and low temperature (Figure 1), we found that at room temperature the apical sprout length was less than $1 \mathrm{~mm}$ at the time of storage of $0 \sim 19 \mathrm{~d}$, on the $20^{\text {th }}$ day, the apical sprout was gradually extended, and on the $37^{\text {th }}$ day, it was more than $2 \mathrm{~mm}$, the dormancy was released. At the low temperature, the apical sprout length was less than $1 \mathrm{~mm}$ at the time of storage of $0 \sim 19 \mathrm{~d}$, it was more than $1 \mathrm{~mm}$, but less than $2 \mathrm{~mm}$ at the time of storage of $20 \sim 48 \mathrm{~d}$, and on the $49^{\text {th }}$ day, it was more than $2 \mathrm{~mm}$, the dormancy was released.

Observed the microscopy of potato apical sprout in 'Mira' at room temperature and low temperature (Figure 2), we found that at room temperature the apical sprout length was less than $1 \mathrm{~mm}$ at the time of storage of $0 \sim 21 \mathrm{~d}$, on the $22^{\text {th }}$ day, the apical sprout was extended slowly, and on the $48^{\text {th }}$ day, it was more than $2 \mathrm{~mm}$, and the dormancy was released. At the low temperature, the apical sprout length was less than $1 \mathrm{~mm}$ at the time of storage of $0 \sim 21 \mathrm{~d}$, it was more than $1 \mathrm{~mm}$, but less than $2 \mathrm{~mm}$ at the time of storage of $22 \sim 52 \mathrm{~d}$, and on the $53^{\text {th }}$ day, it was more than $2 \mathrm{~mm}$, the dormancy was released. Through the changes of apical sprout of the two cultivars at room temperature and low temperature, we found that low temperature can obviously prolong the germination time of 'Favorita', but has little effect on the dormancy time of 'Mira' (Table 1; Table 2).
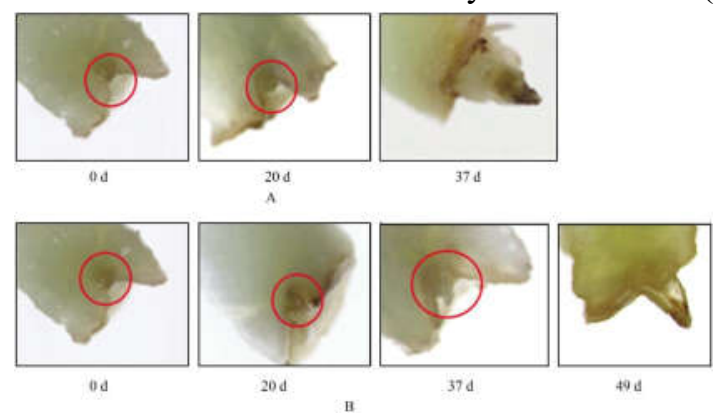

Figure 1 The microscopy of potato apical sprout in 'Favorita' at room temperature and low temperature

Note: A: The microscopy of potato apical sprout in 'Favorita' at room temperature; B: The microscopy of potato apical sprout in 'Favorita' at low temperature

\subsection{The expression of BR synthesis genes in 'Favorita' and 'Mira'}

Analyzed the DWF1 and SMO1 genes expression which were treated with different temperature (Figure 3), we found that the expression of these two genes in 'Favorita' is similar at room temperature. At the time of $0 \sim 29 \mathrm{~d}$, the expression of two genes was low, but it was increasing sharply at the time of $30 \sim 49 \mathrm{~d}$. While, the expression of SMO1 genes in 'Mira' were up-regulation when dormancy was released, and reached maximum on the $53^{\text {th }}$ day. $D W F 1$ tended to be stable at $0 \sim 43 \mathrm{~d}$ and increased sharply on the $44^{\text {th }} \mathrm{d}$ until dormancy was released. We found that the expression of $S M O 1$ and $D W F 1$ was different in different cultivars at low temperature. The expression of $D W F 1$ gene in 'Favorita' is decreased at $0 \sim 50 \mathrm{~d}$; the expression of $S M O 1$ gene is decreased at $20 \sim 49 \mathrm{~d}$, and on the 
$5^{\text {th }}$ day is the peak. The expression of $D W F 1$ gene in 'Mira' is decreased at low temperature, SMO1 gene showed a low expression peak at 15 44 d. The two genes are involved in BR synthesis at room temperature, which affects the growth and development of apical sprout. The expression of $D W F 1$ gene in both cultivars was inhibited at low temperature. The expression of SMO1 gene was inhibited by low temperature in 'Favorita', but not by low temperature in 'Mira'. The result showed that $S M O 1$ has a specific response to low temperature in different potato cultivars.
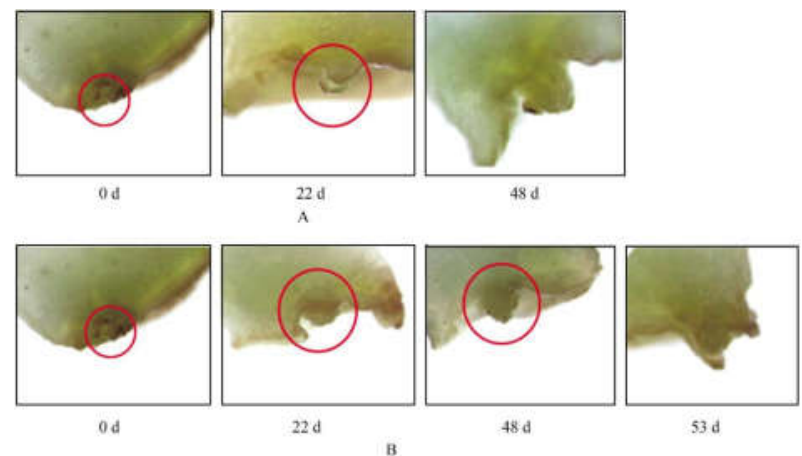

Figure 2 The microscopy of potato apical sprout in 'Mira' at room temperature and low temperature

Note: A: The microscopy of potato apical sprout in 'Mira' at room temperature; B: The microscopy of potato apical sprout in 'Mira' at low temperature

Table 1 Sprout length measurement of "Favorita"

\begin{tabular}{lllllll}
\hline Treatment & Growth length $(\mathrm{mm})$ & & & \\
\cline { 2 - 5 } & $0 \sim 19 \mathrm{~d}$ & $20 \sim 36 \mathrm{~d}$ & $37 \mathrm{~d}$ & $38 \sim 48 \mathrm{~d}$ & $49 \mathrm{~d}$ \\
\hline
\end{tabular}

Room temperature $\left(23^{\circ} \mathrm{C} \pm 2^{\circ} \mathrm{C}\right)$ Sprout length $<1 \quad 1<$ sprout length $<2$ Sprout length $>2 \quad$ Sprout length $>2 \quad$ Sprout length $>2$ Low temperature $\left(4^{\circ} \mathrm{C}\right)$ Sprout length $<1 \quad 1<$ sprout length $<2 \quad 1<$ sprout length $<2 \quad 1<$ sprout length $<2$ Sprout length $>2$

Table 2 Sprout length measurement of "Mira"

\begin{tabular}{lllllll}
\hline Treatment & Growth length $(\mathrm{mm})$ & & & \\
\cline { 2 - 6 } & $0 \sim 21 \mathrm{~d}$ & $22 \sim 47 \mathrm{~d}$ & $48 \mathrm{~d}$ & $49 \sim 52 \mathrm{~d}$ & $53 \mathrm{~d}$ \\
\hline
\end{tabular}

Room temperature $\left(23^{\circ} \mathrm{C} \pm 2^{\circ} \mathrm{C}\right)$ Sprout length $<1 \quad 1<$ sprout length $<2$ Sprout length $>2 \quad$ Sprout length $>2 \quad$ Sprout length $>2$ Low temperature $\left(4^{\circ} \mathrm{C}\right)$ Sprout length $<1 \quad 1<$ sprout length $<2 \quad 1<$ sprout length $<2 \quad 1<$ sprout length $<2 \quad$ Sprout length $>2$
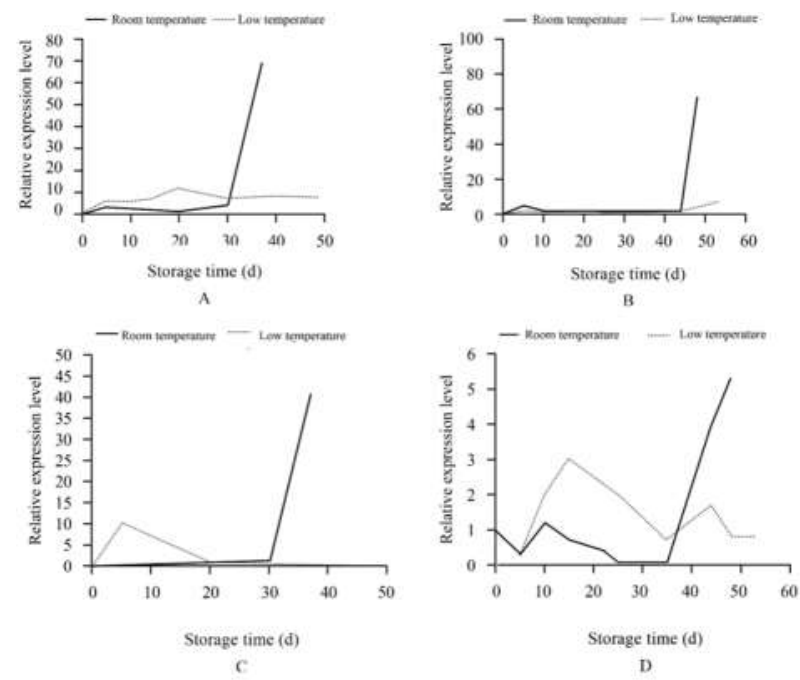

Figure 3 DWF1 and SMO1 genes expression of 'Favorita' and 'Mira' which were treated with room temperature and low temperature Note: A: DWF1 gene expression in 'Favorita'; B: DWF1 gene expression in 'Mira'; C: SMO1 gene expression in 'Favorita'; D: SMO1 gene expression in'Mira' 


\subsection{The expression of BR signal transduction genes in 'Favorita' and 'Mira'}

The expression of BRII and BSK in 'Favorita' and 'Mira' were up-regulation when dormancy was released at room temperature (Figure 4). On the $30^{\text {th }}$ day, the expression of BRII and BSK in 'Favorita' was increasing sharply. While, the expression in 'Mira' was increasing sharply on the $44^{\text {th }}$ day at dormancy. The expression of BRII tended to be stable in two cultivars at low temperature; it showed a low expression peak on the $12^{\text {th }}$ day in 'Favorita'. The expression of BRII was increased in 'Mira' at $0 \sim 15 \mathrm{~d}$, decreased on the $15^{\text {th }}$ day, and then tended to be stable until dormancy was released, it decreased again. The expression of $B S K$ gene was significantly different between the two cultivars treated with low temperature. The expression of BSK gene in 'Favorita' was increased at $0 \sim 19 \mathrm{~d}$, on the $20^{\text {th }}$ day, $B S K$ expression was decreased inhibited by low temperature. $B S K$ gene in 'Mira' showed the first low expression peak on the $15^{\text {th }}$ day treated with low temperature, and increased sharply on the $44^{\text {th }}$ day. The results showed that $B R I$ and $B S K$ genes played an important role in potato germination. The expression of BRII in 'Mira' and 'Favorita' was inhibited by low temperature. The expression of BSK was inhibited by low temperature when stored in 'Favorita' at 22 49 d, while the expression of $B S K$ was not inhibited by low temperature in 'Mira'. BSK had a specific response to low temperature in different potato cultivars.
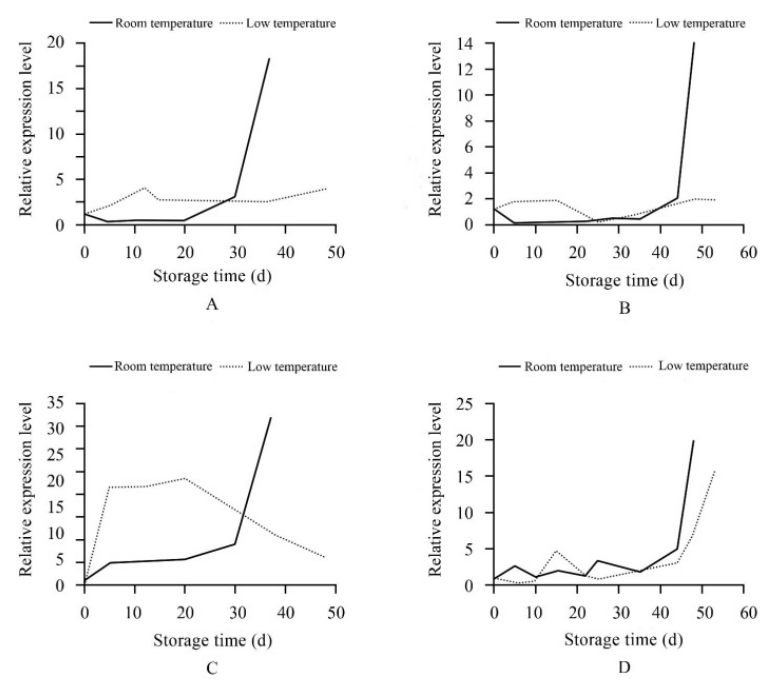

Figure $4 B R I 1$ and $B S K$ genes expression of 'Favorita' and 'Mira' which were treated with room temperature and low temperature Note: A: BRI1 gene expression in 'Favorita'; B: BRII gene expression in 'Mira'; C: BSK gene expression in 'Favorita'; D: BSK gene expression in'Mira'

\subsection{The expression of BR signal regulation genes in 'Favorita' and 'Mira'}

The $C Y C D 3$ gene expression in 'Mira' showed the first peak on the $26^{\text {th }}$ day treated with room temperature, and was increasing sharply on the $35^{\text {th }}$ day. While, CYCD3 gene expression in 'Mira' showed the first peak on the $10^{\text {th }}$ day treated with low temperature, and was increasing sharply on the $44^{\text {th }}$ day (Figure 5B). The CYCD3 gene expression in 'Favorita' was decreased treated with room temperature, and was increasing sharply on the $30^{\text {th }}$ day. But it was decreased inhibited by low temperature (Figure 5A). The results showed that CYCD3 gene has a specific response to low temperature in different potato cultivars.
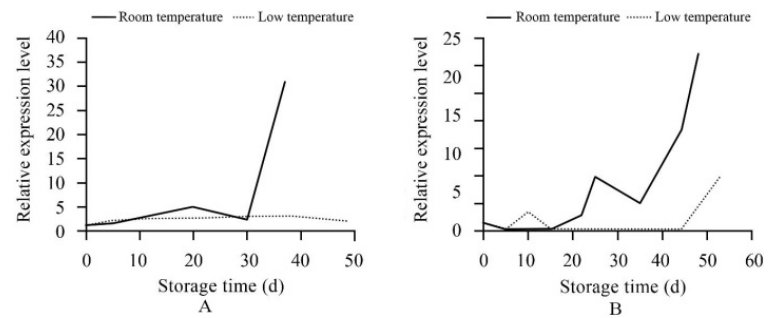

Figure 5 CYCD3 gene expressions of 'Favorita' and 'Mira' which were treated with room temperature and low temperature Note: A: CYCD3 gene expression in 'Favorita'; B: CYCD3 gene expression in 'Mira' 


\section{Discussion}

The results of the microscopy of potato apical sprout in 'Favorita' and 'Mira' at room temperature and low temperature showed that low temperature could inhibit the growth rate of potato apical sprout and prolong its storage period. The storage characteristics of potato were closely related to the cultivars (Pu et al., 2016). And according to the germination of 'Favorita' and 'Mira' at room temperature and low temperature, we could find that the sensitivity of different potatoes to low temperature was significantly different. Suttle (2008) applied auxin to dormant potato and found that the sensitivity of potato to exogenous auxin was different in different dormant period, and the later stage of dormancy was more sensitive to exogenous auxin. From this we could speculate that sensitivity of different cultivars of potato to low temperature in germination stage is different, which results in different effects of low temperature inhibition on germination of different potato.

BR is a necessary signal for tuber to release dormancy and germination. If its synthetic gene expression is inhibited, tuber germination will be blocked. The signal transduction and regulation between BR synthesis-related $S M O 1, D W F 1$ members BRI1, BSK, and CYCD3 is a necessary process for the transformation of plant physiological state (Zhang et al., 2009). Besides, BR plays an important role in improving plant stress resistance at low temperature. Ma (2015) treated corn seeds pretreated with EBR under low temperature stress, and found that the exogenous EBR obviously promoted the germination of the corn seeds and the growth rate of the seedlings at low temperature. This study analyzed the BR synthesis, signal transduction, and activated genes (SMO1, DWF1, BRI1, BSK, CYCD3) expression of 'Favorita' and 'Mira' at different dormancy period with different temperature, and found that these 5 genes expression of 'Mira' and 'Favorita' which were treated with room temperature were up-regulation when potato germination. This is consistent with the results of Zou et al. (2017). The BR synthesis signal transduction gene expression of 'Favorita' was inhibited by low temperature during germination. While the $S M O 1, B S K$, and $C Y C D 3$ genes expression of 'Mira' was not inhibited by low temperature during germination. Therefore, we speculated that the $S M O 1, B S K$, and $C Y C D 3$ genes expression of two cultivars could be affected by the low temperature, which leads to the difference of the effect of two cultivars. And we can effectively inhibit the growth of potato sprouts by inhibiting their expression in the germination of the potato. The results showed that the BR synthesis metabolism is closely related to the outside temperature in addition to its effect on potato tuber dormancy and germination.

\section{Materials and Methods}

\subsection{Materials and reagents}

Potato cultivars 'Favorita' and 'Mira' were provided by the potato research and development center of the Agricultural College of Sichuan Agricultural University.

Reverse transcription kit: RevertAid First Strand cDNA Synthesis, TRIzol, DEPC, and SGExcel FastSYBR Mixture.

\subsection{Materials handling}

The new potato cultivars 'Favorita' and 'Mira' of the same size (7 10 g/per) were selected, and washed with clean water, putting them into closed cartons after healing at room temperature. Each carton was filled with 40 potato seeds, and the cartons were stored at room temperature $(23 \pm 2)^{\circ} \mathrm{C}$ until the middle and late dormancy stages of two cultivars respectively, then stored at room temperature $(23 \pm 2)^{\circ} \mathrm{C}$ and constant temperature freezer $\left(4^{\circ} \mathrm{C}\right)$ respectively. The above steps were repeated three times. The results of the microscopy of potato apical sprout was measured when the sprout was less than $1 \mathrm{~mm}$, between $1 \mathrm{~mm}$ and $2 \mathrm{~mm}$, and more than $2 \mathrm{~mm}$. Taking the sprout eye as the center, collecting a potato cylindrical tissue with a height of $5 \mathrm{~mm}$, and a diameter of $3 \mathrm{~mm}$. This sample was quickly placed in liquid nitrogen and stored at $-80^{\circ} \mathrm{C}$ for RNA extraction.

\subsection{Gene expression determination by qRT-PCR}

TRIzol was used to extract RNA from sample. High salt, ethanol, freeze-thaw, and other treatments were used to remove polysaccharides from potato tubers. The reverse transcription system: The mixture of $1 \mu \mathrm{L}$ Oligo dT, $8 \mu \mathrm{L}$ 
DEPC $\mathrm{H}_{2} \mathrm{O}$, and $3 \mu \mathrm{L}$ RNA was placed in water at $65^{\circ} \mathrm{C}$, and cooled on ice for 2 min immediately after 5 min. Add $4 \mu \mathrm{L} 5 \times$ reaction buffer, $2 \mu \mathrm{L} 10 \mathrm{mmol} / \mathrm{L}$ dNTPs mixture, $1 \mu \mathrm{L}$ RNase inhibitor $(20 \mathrm{U} / \mu), 1 \mu \mathrm{L}$ Reverse Transcriptase $(200 \mathrm{U} / \mu \mathrm{L})$ respectively. Reaction was stopped after $60 \mathrm{~min}$ at $42^{\circ} \mathrm{C}$, and $10 \mathrm{~min}$ at $72^{\circ} \mathrm{C}$. Oligo 6.0 software was used to design its specific primers according to each gene sequence (Table 3). EF1 $\alpha L$ gene was selected as internal reference. $25 \mu \mathrm{L}$ Fluorescence quantitative PCR: $12.5 \mu \mathrm{L} 2 \times$ SGExcel FastSYBR mixture, 10.5 $\mu \mathrm{L}$ RNase-Freedd $\mathrm{H}_{2} \mathrm{O}, 0.5 \mu \mathrm{L}$ upstream and downstream primers, and $1.0 \mu \mathrm{L}$ cDNA. The expression of each gene was detected by the Bio-Rad CFX Connect PCR machine. $2^{-\Delta \Delta \mathrm{Ct}}$ was used to calculate the detection results of relative expression of each gene. The $\Delta \mathrm{Ct}$ value of 'Favorita' and 'Mira' was used as a control at the time of storage for $0 \mathrm{~d}$, respectively. PCR techniques were repeated 3 times (Zou et al., 2017).

Table 3 Primer sequences genes for qRT-PCR test

\begin{tabular}{lll}
\hline Gene & ID & Primer \\
\hline Elongation factor 1 alpha-like (Reference gene) & PGSC0003DMT400014674 & CTTGTACACCACGCTAAGGAG \\
Delta24-sterol reductase 1 & PGSC0003DMT400030799 & ACATTATGGACCTTCTTGTCC \\
Methylsterol monooxygenase 1 & & AGATGCATTCCTATCCTTAAG \\
Protein BR insensitive 1 & PGSC0003DMT400033236 & GAGAGAAACTGAGAATGGAGG \\
BR-signaling kinase & & GTGCTTGATAGAGAAACACAAC \\
Cyclin D3 & PGSC0003DMT400066895 & AGGTGCCTGTTCCACATAGT \\
& PGSC0003DMT400052467 & AGAGAAGACATTATTATTGACACCAGACATA \\
\hline
\end{tabular}

\section{Authors' contributions}

DXN carried out the experimental research, completed the data analysis, and drafted the manuscript. DMS and ZX participated in the experimental design, data analysis and drafted the manuscript. LYN participated in the experimental design and carried out the experimental research. NS participated in the result analysis and draft revision. WXY was in charge of the project, guided experiment design and draft revision. All authors read and approved the final manuscript.

\section{Acknowledgments}

This work was supported by modern agricultural industry technology system of Sichuan potato industry innovation team (Sichuan agricultural letter [2014], No.91) and training funds for academic and technical leaders of Sichuan Province.

\section{References}

Bamberg J.B., 2010, Tuber dormancy lasting eight years in the wild potato Solanum jamesii, Am. J. Pot. Res., 87(2): 226-228 https://doi.org/10.1007/s12230-009-9124-9

Clouse S.D., and Sasse J.M., 1998, Brassinosteroids: essential regulators of plant growth and development, Annu. Rev. Plant Physiol. Plant Mol. Biol., 49: 427-451

https://doi.org/10.1146/annurev.arplant.49.1.427 PMid: 15012241

Fan R., Song B.T., Xie C.H., and Liu J., 2009, Comparison of dormancy and sprouting between potato minitubers produced in spring and autumn seasons, Zhongguo Malingshu (Chinese Potato Journal), 23(5): 277-280

Ma J.H., 2015, Physiological mechanism of EBR promote low temperature stress in maize seed germination, Dissertation for Ph.D., Shanxi Agricultural University, Supervisor: Du H.L., pp.20-30

Pu H.M., Yao C.G., Li Y.S., Liu L.Y., Yang Q.F., and Bai J.M., 2016, Effects of low temperature storage on physiological property of two potato cultivars, Baoxian Yu Jiagong (Storage and Process), 16(5): 1-4, 9

Steber C.M., and McCourt P., 2001, A role for brassinosteroids in germination in Arabidopsis, Plant Physiol., 125(2): $763-769$ 
Suttle J.C., 2008, Effects of synthetic phenylurea and nitroguanidine cytokinins on dormancy break and sprout growth in Russet Burbank minitubers, Am. J. Pot. Res., 85(2): 121 https://doi.org/10.1007/s12230-008-9002-X

Tian J.C., Tian S.L., Ge X., Li S.Q., Li M., and Cheng J.X., 2017, Research advances on storage technology of potato, Baoxian Yu Jiagong (Storage and Process), 17(4): 108-112

Zhang L.Y., Bai M.Y., Wu J., Zhu J.Y., Wang H., Zhang Z., Wang W., Sun Y., Zhao J., Sun X., Yang H., Xu Y., Kim S. H., Fujioka S., Lin W.H., Chong K., Lu T., and Wang Z.Y., 2009, Antagonistic HLH/bHLH transcription factors mediate brassinosteroid regulation of cell elongation and plant development in rice and Arabidopsis, Plant Cell, 21(12): 3767-3780 https://doi.org/10.1105/tpc.109.070441 PMid:20009022 PMCid:PMC2814508

Zhang R., Chen Y.C., Yu T.Y., and Li L.F., 2012, Study on potato storage characteristics and conditions, Nongye Keji Yu Zhuangbei (Agricultural Science \& Technology and Equipment), (9): 67-68

Zhong L., Deng J.C., Wang L.J., Zheng S.L., Dou P., Wang X.L., and Yuan J.C., 2017, Effect of plant growth regulators on germination and oxidase activity during storage of potato tubers, Caoye Xuebao (Acta Prataculturae Sinica), 26(7): 147-157

Zou X., Deng M.S., Li L.Q., Yu J.L., Ding F., Huang X.L., Peng J., Shuai Y., Cai C.C., and Wang X.Y., 2017, Expression changes of genes related to brassinosteroid biosynthesis and signal transduction during potato storage and its effect on tuber sprouting, Zuowu Xuebao (Acta Agronomica Sinica), 43 (6): 811-820

https://doi.org/10.3724/SP.J.1006.2017.00811 